\title{
Age features of suicidal behavior of adolescent girls
}

Grigoryeva A.A.

V. Serbsky National Medical Research Centre for Psychiatry and Narcology, Moscow, Russia

(No potential conflict of interest)

Anonymous screening study of schoolchildren:

$n=865$ girls, $10-18$ years

"Method of body modification and self-harm" (Poljskaja N.A, 2017);

"Suicidal personality-19" (Yunatskevich P.I., 2009);
The choice of type of autoagressive behavior is influenced by gender features (Yang, Feldman, 2018, Gratz, 2001; Klonsky, Oltmanns,

Turkheimer, 2003; Muehlenkamp, Gutierrez, 2004).

The frequency of completed suicides among males is higher and is $4: 1$ in relation to females, but the number of suicide attempts among girls is much higher (Jahns, Taneli, Warnke, 2012).

\begin{tabular}{|c|c|c|c|c|}
\hline & $\mathbf{p}$ & $\mathbf{1 0 - 1 1}$ age & $\mathbf{1 2 - 1 5}$ age & $\mathbf{1 6 - 1 8}$ age \\
\hline The level of suicide risk & 0,012 & 2,25 & 3,29 & 3,03 \\
\hline $\begin{array}{c}\text { Positive attitude to body } \\
\text { modifications and self- } \\
\text { harm }\end{array}$ & 0,001 & 1,18 & 1,16 & 1,48 \\
\hline \begin{tabular}{c} 
The presence of self-harm \\
\hline
\end{tabular} & 0,010 & 2,87 & 3,95 & 4,34 \\
\hline
\end{tabular}

*single-factor analysis of variance was used, SPSS17

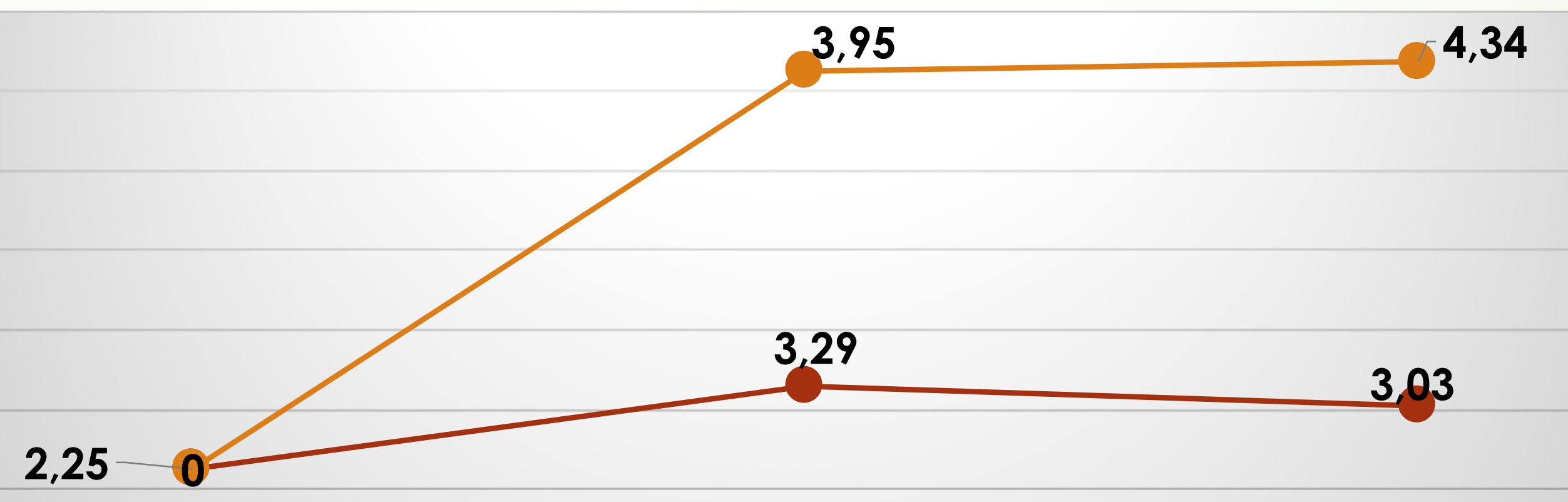

10-11 AGE

12-15 AGE

16-18 AGE

-The level of suicide risk -The presence of self-harm

Conclusions:

Suicidal behavior of adolescent girls increases in the period of 12-15

years, followed by an increase in the risk of self-injury behavior in 16-18 years. 